\title{
Efficacy of scopolamine transdermal patch in children with sialorrhea in a pediatric tertiary care hospital
}

\author{
Majed Al Jeraisy ${ }^{1,2,3^{*}}$, Maissa AlFuraih ${ }^{4}$, Raghad AlSaif ${ }^{4}$, Bushra AlKhalifah $^{5}$, Hazza AlOtaibi ${ }^{1}$ and \\ Mostafa A. Abolfotoun ${ }^{2,3}$
}

\begin{abstract}
Background: Drooling is common in children with neurological disorders, but its management is very challenging, Scopolamine transdermal patch (STP) appears to be useful in controlling drooling, although it is not approved for this indication and there are limited clinical studies about its effectiveness. This study aimed (1) to assess the impact of STP use on the severity of drooling and on the frequency of emergency department (ED) and hospital readmission (RA) visits related to drooling, and (2) to determine the level of family satisfaction with STP when used in children with neurological disorders.
\end{abstract}

Methods: This is a retrospective cohort study of all pediatric patients aged 3-14 years, with non-progressive neurodevelopmental disability, who used STP for more than one year during the period between April 2015 and July $2018(n=44)$. Data on demographics, clinical status, comorbidities, STP dose and duration, other medications, ED and RA visits were collected. Follow-up phone-call interviews with parents/caregivers were performed using a parent-reported frequency and severity rating scale of sialorrhea. Absolute and relative risk reductions were calculated to assess the impact of STP on ED and RA visits. Significance was considered at $p$-value of $\leq 0.05$.

Results: STP use showed significant reduction in severity of drooling $(p<0.001)$, wiping of the child's mouth $(p<$ $0.001)$, bibs or clothing changes $(p<0.001)$, choking and aspiration of saliva $(p=0.001)$. The Relative Risk Reduction of the drooling-related ED and RA visits were $86 \%$ and $67 \%$ respectively. Nearly two-thirds (60\%) of caregivers were satisfied with using STP.

Conclusions: This is the first study of its kind done in Saudi Arabia demonstrating favorable impact of STP use by children on the consequences associated with drooling and with the frequency of ER and RA visits due to drooling. Development of a medication use protocol is recommended to standardize STP treatment in order to optimize its effectiveness. This study serves as baseline information for future prospective interventional studies.

Keywords: Drooling, Transdermal, Efficacy, Scopolamine, Hyoscine, Saudi, Neurological disorders, Cerebral palsy, Hospital readmission, ER visits

\footnotetext{
* Correspondence: Jeraisym@NGHA.MED.SA

${ }^{1}$ Pharmaceutical Care Department, King Abdullah Specialized Children Hospital, Ministry of National Guard, Riyadh, Saudi Arabia

${ }^{2}$ King Abdullah International Medical Research Center (KAIMRC), Ministry of

National Guard-Health Affairs, Riyadh, Saudi Arabia

Full list of author information is available at the end of the article
}

C C The Author(s). 2020 Open Access This article is licensed under a Creative Commons Attribution 4.0 International License, which permits use, sharing, adaptation, distribution and reproduction in any medium or format, as long as you give appropriate credit to the original author(s) and the source, provide a link to the Creative Commons licence, and indicate if changes were made. The images or other third party material in this article are included in the article's Creative Commons licence, unless indicated otherwise in a credit line to the material. If material is not included in the article's Creative Commons licence and your intended use is not permitted by statutory regulation or exceeds the permitted use, you will need to obtain permission directly from the copyright holder. To view a copy of this licence, visit http://creativecommons.org/licenses/by/4.0/. The Creative Commons Public Domain Dedication waiver (http://creativecommons.org/publicdomain/zero/1.0/) applies to the data made available in this article, unless otherwise stated in a credit line to the data. 


\section{Background}

Sialorrhea (drooling) is a biological condition characterized by salivary incontinence or the automatic spillage of saliva over the lower lip. The average saliva secretion in healthy individual is $0.5-1.5 \mathrm{~L} /$ day [1]. Sialorrhea is abnormal over the age of about 4 years [2], and is often found in children with neurological disorders. It could be due to failure to retain saliva inside the mouth, or difficulty with swallowing [3]. It was prevalent in $40 \%$ of a population-based study of 7 to 14 -year-old children with cerebral palsy (CP) [4], and in $58 \%$ of children with CP attending special schools in the UK [5], while the pooled prevalence estimate determined in a recent metaanalysis was $44 \%$ [6]. Sialorrhea has a negative impact on functional and clinical outcomes for patients, families, and caregivers.

Patients with sialorrhea will manifest this problem in one of two principle ways. Anterior sialorrhea is when patients have excessive anterior or forward spillage of saliva from their mouths onto their faces and clothes, causing difficulty with cleanliness, skin care, and socialization [7-9]. Posterior sialorrhea occurs when the trigger to swallow is impaired or missing. These patients have excessive posterior spillage of saliva into the hypopharynx, and pooled saliva may lead to congested breathing, coughing, gagging, vomiting, and at times aspiration into the trachea [10]. Unrecognized and silent pneumonia can occur [11].

Reported treatment options have included behavioral modification therapy, oral or topical anticholinergic medications, surgical excision of salivary glands or duct relocation, and chemodenervation with botulinum toxin [12]. Pharmacological medications such as glycopyrrolate, an anticholinergic agent, decrease saliva secretion through the parasympathetic autonomic nervous system [13]. Glycopyrrolate is approved by the US Food and Drug Administration (USFDA) for drooling in pediatric patients with neurologic conditions [14]. Scopolamine is an anticholinergic agent with antiemetic and hypnoticsedative properties. As scopolamine blocks parasympathetic innervation of the salivary glands, one of its indications is to reduce saliva secretion [15].

Scopolamine transdermal patch (STP) has been used to decrease salivation in adult patients and was reported in 1984 by Dettman et al. [16] and Gordon et al. in 1985 [17] with a significant reduction of the salivary flow. A double-blind, placebo-controlled study in 1994 [18] on ten developmentally delayed children supported earlier reports of the safety and efficacy of STP for reducing excessive drooling. Another study in Nijmegen, 2006 [19] conducted in an out-patient clinic on 45 pediatric patients with $\mathrm{CP}$ and severe drooling, using scopolamine patch and botulinum toxin, showed that both scopolamine and botulinum toxin significantly decreased salivary flow. In 2010, a prospective randomized double-blind, crossover, placebo-controlled clinical trial [20] done in Spain for 30 patients with severe disabilities came up with significant reduction in drooling. A multi-center randomized controlled trial was initiated to identify whether glycopyrronium or scopolamine was more effective in treating drooling in children with nonprogressive neurodisability, and showed that scopolamine and glycopyrrolate were both clinically effective in treating drooling, but scopolamine produced more problematic side effects leading to a greater chance of treatment cessation [21]. In a recent study by Reid et al., [22] benzhexol, glycopyrrolate, and scopolamine reduced drooling, but improvement was offset by adverse side effects, glycopyrrolate performed best. A number of side effects have been reported with STP such as; blurred vision, sedation, dry mouth, drowsiness, dizziness, increased seizure frequency, constipation, urinary retention, difficulties in hot weather due to decreased sweating and mild itching/redness at the application site [21, 23, 24].

Despite the abundance of reports on the efficacy and safety profiles of each treatment option, definitive conclusions are difficult to draw, given the heterogeneous nature of the patient populations studied and the different outcome measures used in the various studies [12]. The aims of this study were: (1) to assess the impact of scopolamine transdermal patch use on the severity and frequency of drooling, (2) to assess its efficacy in pediatric patients with regards to the frequency of drooling-related emergency department (ED) visits and hospital readmission (RA) visits, and (3) to determine the level of satisfaction of families and/or caregivers and their convenience before and after using this medication.

\section{Methods}

\section{Study design}

This was a retrospective cohort study among pediatric patients aged 3 to 14 years, with non-progressive neurodevelopmental disability, using STP for more than one year during the period between April 2015 and July 2018.

\section{Study setting}

This study was conducted at King Abdullah Specialized Children's Hospital (KASCH), a tertiary pediatric hospital in Riyadh, Saudi Arabia, with a total capacity of 552 beds. STP is a non-formulary and restricted medication in the hospital, and there are no hospital guidelines or protocol to standardize its use. The usual hospital practice of managing patients with excessive salivation is to start them on glycopyrrolate for a week, if there is no response [non-response was defined as no change in the frequency of salivation as mentioned by the child's parent/caregiver], then to switch to STP, starting with $1 / 4$ 
patches $(0.375 \mathrm{mg})$ then gradually increased to full patches $(1.5 \mathrm{mg})$, or to the maximum tolerated dose of their medication. STPs were placed on cleaned skin behind the ear once daily. The backing of the patch was covered to expose the prescribed portion of it, and an occlusive dressing was then applied over the patch as per usual practice [3].

\section{Study subjects}

This study included all pediatric patients aged 3 to 14 years, with non-progressive neurodevelopmental disability, who started on glycopyrrolate then shifted to STP for a minimum of one year during the period between April 2015 - the date of launching a new electronic medical record (EMR) system in the hospital- and July 2018, and who were still alive during the study period $(n=44)$. This period was chosen so as to allow for more accurate data to be collected from the EMR about the management of drooling. Of the records of 69 children, those with progressive neurodevelopmental disability, those whose parents could not be reached for interview, and those who were on STP for less than one year at the time of study were all excluded. All patients who were on dual therapy (glycopyrrolate + Scopolamine) were also excluded.

\section{Data collection}

The following data were retrieved from electronic medical records of all children who were on STP: Demographic characteristics and clinical data, frequency of ED and RA visits, comorbidities and dose of STP and its duration. The severity of drooling was determined subjectively using a parent-reported frequency and severity rating scale of sialorrhea [25, 26]. Follow-up interviews with parents/ caregivers of the patients were performed, one year or more after commencing the patches, either by a phone call for the outpatients $(n=38)$ or face-to-face interview if the patient was hospitalized $(n=06)$. The questionnaire was composed of 5-point scaled questions, to assess the frequency of different consequences associated with drooling (1-none, 2-mild, 3-moderate, 4-severe, and 5-Very severe) [26]. Parent/caregiver was asked one more question to assess their satisfaction with the use of STP (1-Not satisfied, 2-Less satisfied, 3-Neutral, 4-Satisfied and 5-Very satisfied). There was an independent witness from outside the research team witnessing the consent process with parents over the phone, with their agreement to participate in the interview and allow for their children's recorded data be used in research. The study was approved by the Institutional Review Board (IRB) of Ministry of National GuardHealth Affairs, Riyadh, Saudi Arabia,[Ref.\#RSS18/008/R].

\section{Data analysis:}

The data was analyzed using SPSS (Version 25). Descriptive statistics such as; percentage, mean standard deviations
(SD), median and interquartile range (IQR) were used. To compare between the mean score of consequences on the child due to drooling before and after STP use, Wilcoxon signed-ranks test was used. The relative risk reduction (RRR) and the absolute risk reduction (ARR) and their corresponding 95\% Confidence intervals, and the relative risks (RR) were all calculated, to assess the impact of using STP on the frequency of ED visits and hospital admission visits related to drooling. There was no missing data. Significance was considered at $p$-value of $<0.05$.

\section{Results}

Records of 69 patients were reviewed, 44 (63.8\%) met the inclusion criteria. Children with progressive neurodevelopmental disability $(n=19)$, those whose parents could not be reached for interview $(n=04)$, and those who were on STP for less than one year at the time of study $(n=02)$ were all excluded. Patients manifested sialorrhea in one of two forms; posterior drooling $(n=29$, $66 \%)$ and anterior drooling $(n=15,34 \%)$. Demographics of the included patients are presented in Table 1. Male/ female ratio was 1:1.1, with a median age of 93 months $(\mathrm{IQR}=64)$, median height of $105 \mathrm{~cm}(\mathrm{IQR}=32)$ and median weight of $16.8 \mathrm{~kg}$. (IQR =15.9). Comorbidities included epilepsy (79.5\%), global developmental delay $(61.4 \%)$ and gastro-esophageal reflux disease (59.1\%). With regard to scopolamine adverse effects, one-third of all patients $(36.4 \%)$ had tachycardia, $13.6 \%$ had visual disturbance, and $9.1 \%$ had urinary retention. Dry mouth, skin irritation or drowsiness were not among the side effects mentioned by parents/caregivers. A total of 29 children were receiving regular suction, and $60 \%$ of their

Table 1 Personal and disease characteristics of children with Sialhorrea

\begin{tabular}{ll}
\hline Variable & $\mathbf{N = 4 4}$ \\
\hline Patient's characteristics & \\
Sex (M/F) & $23 / 21(1.1: 1)$ \\
Age in months [Md \& IQR] & $93.0(64)$ \\
Height in cm. [Md \& IQR] & $105(32)$ \\
Weight in $\mathrm{kg} .[\mathrm{Md} \& \mathrm{IQR}]$ & $16.8(15.9)$ \\
Comorbidities & $\boldsymbol{a}$ \\
Epilepsy [n, \%] & \\
GDD [n, \%] & (35) 79.5 \\
GERD[n, \%] & (27) 61.4 \\
Side effects of STP use ${ }^{\boldsymbol{a}}$ & (26) 59.5 \\
$\begin{array}{l}\text { Eye problems [n, \%] } \\
\text { Urinary retention [n, \%] }\end{array}$ & (6) 13.6 \\
Tachycardia [n, \%] & (4) 9.1 \\
a figures for this variable are not mutually exclusive, GERD Gastrointestinal \\
reflux disease, GDD Global developmental delay, Md Median, IQR Interquartile \\
range, STP Scopolamine transdermal patch
\end{tabular}


parents/caregivers reported decrease in suction after using STP.

Table 2; Fig. 1 show the distribution of children with neurological disorders according to the frequency (mean score \pm SD) and severity of different consequences associated with drooling before and after STP use. The proportion of children with severe/very severe drooling was reduced significantly from $87.5 \%$ of children before STP use to $15.6 \%$ after STP use $(p<0.001)$. Severe/very severe need for wiping of the child's mouth was prevalent in $75 \%$ of children before STP use, and it was reduced significantly to $21.8 \%$ after STP use $(p<0.001)$. Severe/very severe need for clothing changes were prevalent in $56.2 \%$ and $12.5 \%$ of all children before and after STP use, respectively $(p<0.001)$. Choking and aspiration of saliva was severe/very severe in $18.7 \%$ of children before STP use, while none of the children suffered from this severe choking after STP use $(p=0.001)$. Parents and/or caregivers of the majority of children with sialorrhea (59.4\%) were satisfied/very satisfied with STP use by the children (Table 2 ).

Table 3 shows the ED and the RA visits of children due to drooling before and after STP use. The rate of ED visits due to drooling dropped from 33\% before STP use to $5.4 \%$ after, with an ARR of ED visits of $27.6 \%$ (95\% CI: $9.4 \%-45.6 \%, p<0.001$ ), and RRR of $86 \%$. Relative risk was 0.16 reflecting a reduction of the rate of ED visits by $84 \%$ after STP use. With regard to RA of children due to drooling, the rate of RA dropped from $44.4 \%$ before STP use to only $8.7 \%$ after, with an ARR of 35.7\% (95\% CI: $15.7 \%-55.7 \%, p<0.001$ ), and RRR of $67.1 \%$. Relative risk was 0.20 , reflecting $80 \%$ reduction in RA rate after STP use.

\section{Discussion}

A number of studies have detected a reduction in saliva secretion with STP treatment among children with neurodevelopmental disorders, yet efficacy varied between patients [25, 27-29]. Our study showed favorable impacts of STP use by children on the consequences associated with drooling, with a significant reduction in the proportion of children with severe/very severe drooling, need for wiping of the child's mouth, need for clothing changes and choking. The results of the present study were consistent with those published by other authors such as Mato et al. [20] who studied 15 patients with mental retardation, where treatment with scopolamine led to a significant reduction in drooling at 24,48 , and $72 \mathrm{~h}$ after application of the skin patch, compared with placebo. Our findings were also in agreement with a previous study [25] reporting that drooling completely resolved in one third of cases in a group of 11 children with mental retardation and moderate-severe drooling. However, this medication should be used with caution, considering the side effects shown in the present study, where more than one third of all patients suffered tachycardia. Moreover, around $80 \%$ of patients presented with epilepsy as a comorbidity, and one of the side effects of scopolamine is that it could interact with anti-epilepsy medication and that it could increase seizures.

Recently the DRI trial of Parr et al. [21] showed that scopolamine and glycopyrrolate were both clinically effective in treating drooling, but scopolamine produced more problematic side effects leading to a greater chance of treatment cessation. The timing of drug administration may explain this discrepancy between the results of the trial and those of our study, where in Parr's trial children were randomly assigned

Table 2 Consequences associated with drooling before and after scopolamine skin patch and family satisfaction among children with drooling

\begin{tabular}{|c|c|c|c|c|c|c|c|c|c|}
\hline \multirow[b]{3}{*}{$\begin{array}{l}\text { Consequences associated } \\
\text { with drooling }\end{array}$} & \multirow{3}{*}{$\begin{array}{l}\text { Scopolamine } \\
\text { STP use }\end{array}$} & \multicolumn{7}{|c|}{ Severity of Sialorrhea } & \multirow{3}{*}{$\begin{array}{l}\text { Statistical } \\
\text { significance }^{\text {a }} \\
P \text {-value }\end{array}$} \\
\hline & & \multirow{2}{*}{$\begin{array}{l}\text { None } \\
\%\end{array}$} & \multirow{2}{*}{$\begin{array}{l}\text { Mild } \\
\%\end{array}$} & \multirow{2}{*}{$\begin{array}{l}\text { Moderate } \\
\%\end{array}$} & \multirow{2}{*}{$\begin{array}{l}\text { Severe } \\
\%\end{array}$} & \multirow{2}{*}{$\begin{array}{l}\text { Very severe } \\
\%\end{array}$} & \multicolumn{2}{|c|}{ Severity score } & \\
\hline & & & & & & & Mean & SD & \\
\hline \multirow[t]{2}{*}{ Frequency of drooling } & Before & 0.0 & 3.1 & 9.4 & 31.3 & 56.2 & 4.41 & 0.80 & $P<0.001$ \\
\hline & After & 28.1 & 31.3 & 25 & 9.4 & 6.2 & 2.34 & 1.18 & \\
\hline \multirow{2}{*}{$\begin{array}{l}\text { Frequency of wiping of } \\
\text { the child's mouth }\end{array}$} & Before & 3.1 & 3.1 & 18.8 & 9.4 & 65.6 & 4.31 & 1.09 & $P<0.001$ \\
\hline & After & 31.3 & 37.5 & 9.4 & 15.6 & 6.2 & 2.28 & 1.25 & \\
\hline \multirow{2}{*}{$\begin{array}{l}\text { Frequency of bibs or } \\
\text { clothing changes }\end{array}$} & Before & 9.4 & 12.5 & 21.9 & 28.1 & 28.1 & 3.53 & 1.29 & $P<0.001$ \\
\hline & After & 46.9 & 34.4 & 6.2 & 9.4 & 3.1 & 1.88 & 1.10 & \\
\hline \multirow{2}{*}{$\begin{array}{l}\text { Choking and aspiration } \\
\text { of saliva }\end{array}$} & Before & 56.3 & 6.2 & 18.8 & 12.5 & 6.2 & 2.06 & 1.37 & $P=0.001$ \\
\hline & After & 84.4 & 12.5 & 3.1 & 0.0 & 0.0 & 1.19 & 0.47 & \\
\hline \multirow[t]{2}{*}{ Family satisfaction } & \multicolumn{2}{|l|}{$\begin{array}{c}\text { Unsatisfied } \\
\%\end{array}$} & \multicolumn{2}{|c|}{$\begin{array}{l}\text { Less satisfied } \\
\%\end{array}$} & \multicolumn{2}{|l|}{$\begin{array}{l}\text { Neutral } \\
\%\end{array}$} & \multicolumn{2}{|l|}{$\begin{array}{l}\text { Satisfied } \\
\%\end{array}$} & $\begin{array}{c}\text { Very satisfied } \\
\%\end{array}$ \\
\hline & \multicolumn{2}{|l|}{12.5} & \multicolumn{2}{|l|}{6.2} & \multicolumn{2}{|l|}{21.9} & \multicolumn{2}{|l|}{12.5} & 46.9 \\
\hline
\end{tabular}

${ }^{a}$ Wilcoxon signed-ranks test was applied 


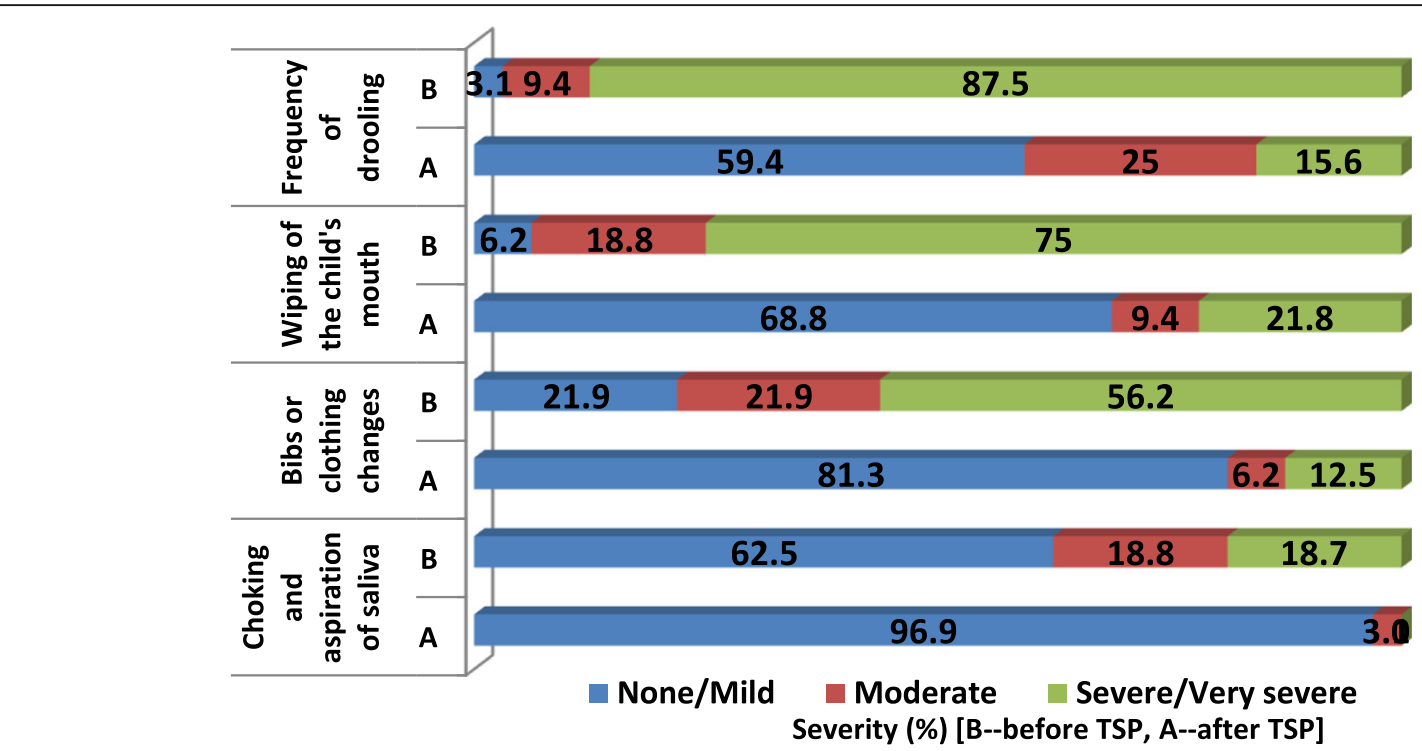

Fig. 1 Severity of consequences associated with sialorrhea before and after scopolamine STP use

to these two medications, at the same time, while in our study, the situation is different, as the aim was to assess retrospectively the STP outcome among only those who had not shown a positive response to glycopyrrolate. This means that our study reflected the STP treatment outcome only among those who did not respond positively to glycopyrrolate, and did not investigate the glycopyrrolate treatment outcome for those who had responded to it positively. Meanwhile, the outcome of scopolamine in our study could be confounded by some factors such as; the type of drooling [anterior and posterior], scopolamine dosage, duration of treatment, and previous medications. Thus, a large scale prospective study is necessary to clarify this point in our setting.

The difficulty for quantifying drooling in patients with disabilities may explain the variability of results, with efficacies between $19 \%$ and $67 \%$ being reported in the literature $[25,28,29]$. In the present study, we relied upon more objective measures of impact of STP use on posterior drooling, which is the impact on the frequency of ED and RA visits related to drooling. In our study, the RRR of the drooling-related ED and RA visits were 86\% and $67 \%$ respectively, with $84 \%$ and $67.1 \%$ reductions in ED and RA visits respectively. This may explain the favorable impact on the quality of life of the children

Table 3 Risk reduction on emergency department (ED) visits and hospital readmission (RA) visits due to scopolamine patch use among children with drooling

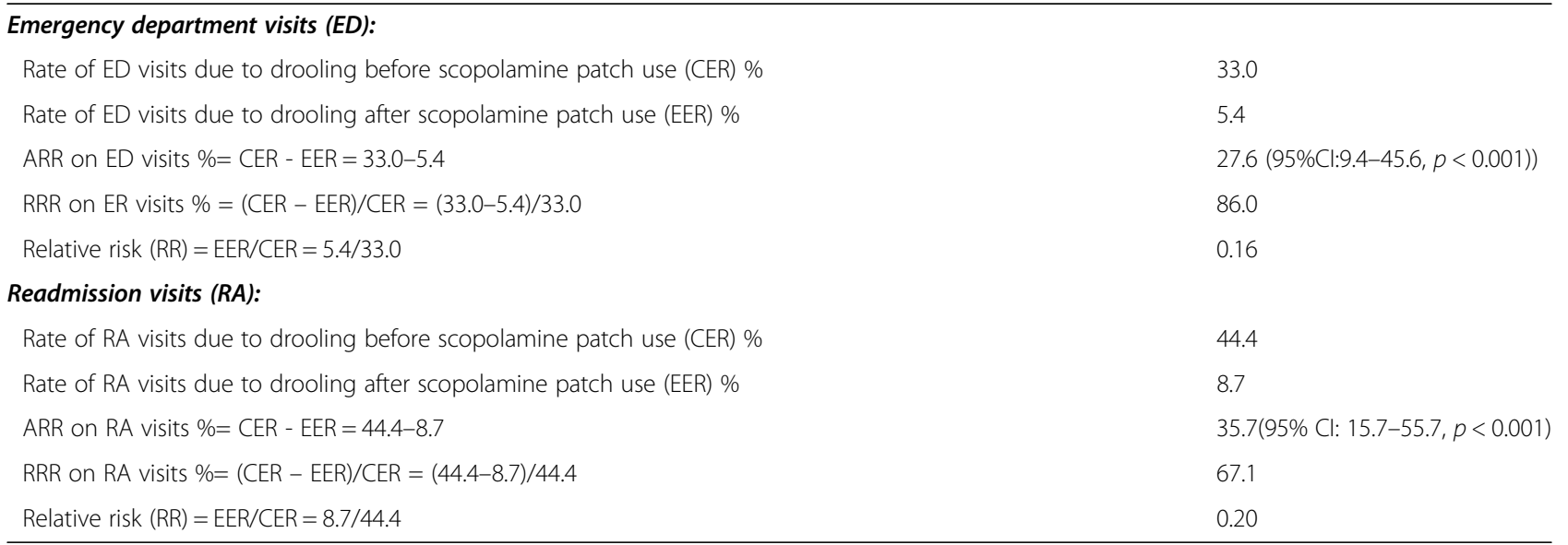


under scopolamine use as well as satisfaction of their families of its use.

\section{Strengths and limitations}

The main strength of this study is that it is the first in Saudi Arabia demonstrating favorable impact of STP use in drooling among children with neurological disorders. With regards to its limitations, the severity of drooling was determined subjectively using their parents/caregivers' frequency and severity rating scales of sialorrhea, with a possible recall bias. The use of different methods of interview [face to face and phone calls] might add more possible information bias. A potential limitation was the inclusion of patients who were using STP for more than one year, and these were the patients who had a more positive effect of the medication and less side effects than those who only used STP for shorter period of time, and stopped its use probably due to its side effects or insufficient effect. This may lead to an increase in the favorable impact of STP use, and influence the conclusion of the study.

\section{Conclusions}

To our knowledge, there are no similar studies conducted in Saudi Arabia to assess the effectiveness and safety of STP in pediatric patients. The results showed that, after using STP, there was significant reduction in the severity of drooling, wiping of the child's mouth, bibs or clothing changes, choking and aspiration of saliva, reduction in the rate of ED and RA visits, and favorable level of family satisfaction with medication. Our findings were consistent with previous studies. This study could serve as baseline information for future prospective interventional studies on the appropriate timing, duration and dosage of STP treatment for pediatric patients with drooling.

\section{Abbreviations \\ KAMC: King Abdulaziz Medical city; MNG-HA: Ministry of National Guard- Health Affairs; KASCH: King Abdullah Specialized Children's Hospital; IRB: Institutional Review Board; STP: Scopolamine transdermalpatch; ED: Emergency department; RA: Readmission; ARR: Absolute risk reduction; RRR: Relative risk reduction; RR: Relative risk; USFDA: US food and drugadministration}

\section{Acknowledgements}

This study was fully supported by King Abdullah International Research Center (KAIMRC), Riyadh, Saudi Arabia. It was approved by the IRB of Ministry of National Guard-Health Affairs, Riyadh, Saudi Arabia [Ref.\#RSS18/008/R]. It was presented in a poster during the 10th Research Summer School program at KAIMRC, August, 2018.

\section{Authors' contributions}

MA1 \& MA2 and MAA contributed to concept development, manuscript preparation and final writing, RA \& BA and HA contributed to concept development and data collection, and MAA \& MA \& RA and BA Contributed to research proposal writing, data collection, analysis and interpretation, and manuscript drafting. All authors read and approved the final manuscript.

\section{Funding}

None.

\section{Availability of data and materials}

Most of the data supporting our findings is contained within the manuscript, and all others, excluding identifying/confidential respondent data, will be shared upon request.

\section{Ethics approval and consent to participate}

This research was approved by the Institutional Review Board (IRB) of The Ministry of National Guard-Health Affairs. Riyadh, Saudi Arabia. Parent/caregiver was asked to assess their satisfaction with the use of STP. There was an independent witness from outside the research team witnessing the consent process with parents over the phone, with their agreement to participate in the interview and allow for their children's recorded data be used in research.

\section{Consent for publication}

Not applicable.

\section{Competing interests}

The authors declare that they have no competing interests.

\section{Author details}

${ }^{1}$ Pharmaceutical Care Department, King Abdullah Specialized Children Hospital, Ministry of National Guard, Riyadh, Saudi Arabia. ${ }^{2}$ King Abdullah International Medical Research Center (KAIMRC), Ministry of National Guard-Health Affairs, Riyadh, Saudi Arabia. ${ }^{3}$ College of Pharmacy, King Saud Bin Abdulaziz University for Health Sciences Ministry of National Guard-Health Affairs, Riyadh, Saudi Arabia. ${ }^{4}$ College of Pharmacy, King Saud University, Riyadh, Saudi Arabia. ${ }^{5}$ College of Pharmacy, Qassim University, Qassim, Saudi Arabia.

Received: 29 January 2020 Accepted: 10 September 2020 Published online: 17 September 2020

\section{References}

1. Finkelstein DM, Crysdale WS. Evaluation and management of the drooling patient. J Otolaryngol. 1992;21:414-8.

2. van Hulst $K$, van den Engel-Hoek $L$, Geurts $A C H$, Jongerius $P H$, van der Burg JJW, Feuth T, et al. Development of the Drooling Infants and Preschoolers Scale (DRIPS) and reference charts for monitoring saliva control in children aged 0-4 years. Infant Behav Dev. 2018:50:247-56.

3. Parr JR, Weldon E, Pennington L, Steen N, Williams J, Fairhurst C, et al. The drooling reduction intervention trial (DRI): A single blind trial comparing the efficacy of glycopyrronium and hyoscine on drooling in children with neurodisability. Trials. 2014;15(1):1-8.

4. Reid SM, McCutcheon J, Reddihough DS, Johnson H. Prevalence and predictors of drooling in 7- to 14-year-old children with cerebral palsy: a population study. Dev Med Child Neurol. 2012;54(11):1032-6. doi:https://doi. org/10.1111/j.1469-8749.2012.04382.

5. Tahmassebi JF, Curzon MEJ. Prevalence of drooling in children with cerebral palsy attending special schools. Dev Med Child Neurol. 2003;45:613-7 613.

6. Speyer R, Cordier R, Kim JH, Cocks N, Michou E, Wilkes-Gillan S. Prevalence of drooling, swallowing, and feeding problems in cerebral palsy across the lifespan: a systematic review and meta-analyses. Dev Med Child Neurol. 2019;61(11):1249-58.

7. Hockstein NG, Samadi DS, Gendron K, Handler SD. Sialorrhea: a management challenge. Am Fam Physician. 2004;69(11):2628-34.

8. Mato Montera A, Limeres Posse J, Tomás Carmona I, Fernández Feijoo J, Diz Dios P. Control of drooling using transdermal scopolamine skin patches. A case report. Med Oral Patol Oral Cir Bucal. 2008;13(1):13-6.

9. McGeachan AJ, McDermott CJ. Management of oral secretions in neurological disease. Pract Neurol. 2017;17(2):96-103.

10. Jongerius PH, van Hulst K, van den Hoogen FJ, Rotteveel JJ. The treatment of posterior drooling by botulinum toxin in a child with cerebral palsy. J Pediatr Gastroenterol Nutr. 2005;41(3):351-3.

11. Gisel EG, Applegate-Ferrante T, Benson J, Bosma JF. Oral-motor skills following sensorimotor therapy in two groups of moderately dysphagic children with cerebral palsy: aspiration vs nonaspiration. Dysphagia. 1996;11:59-71.

12. Alrefai AH, Aburahma SK, Khader YS. Management of sialorrhea in children with cerebral palsy: a double-blind placebo controlled trial. Clin Neurol Neurosurg. 2009;111(1):79-82. 
13. Lakraj AA, Moghimi N, Jabbari B. Sialorrhea. Anatomy, pathophysiology and treatment with emphasis on the role of botulinum toxins. Toxins (Basel). 2013;5(5):1010-31.

14. Garnock-Jones KP. Glycopyrrolate Oral Solution. Pediatr Drugs. 2012; 14(4):263-9

15. Dohar JE. Sialorrhea \& aspiration control - A minimally invasive strategy uncomplicated by anticholinergic drug tolerance or tachyphylaxis. Int J Pediatr Otorhinolaryngol. 2019;116:97-101.

16. Dettman CE. Suppression of salivation in wind-instrument players with scopolamine[letter]. N Engl J Med. 1984;310:1396.

17. Gordon C, Ben-Aryeh H, Attias J, Szargel R, Gutman D. Effect of Transdermal Scopolamine on Salivation. The Journal of Clinical Pharmacology. 1985;25(6): 407-12.

18. Lewis DW, Fontana C, Mehallick LK, Everett Y. Transdermal Scopolamine for Reduction of Drooling in Developmentally Delayed Children. Dev Med Child Neurol. 1994;36(6):484-6.

19. Van der Burg JJW, Jongerius PH, Van Hulst K, Van Limbeek J, Rotteveel JJ. Drooling in children with cerebral palsy: Effect of salivary flow reduction on daily life and care. Dev Med Child Neurol. 2006;48(2):103-7.

20. Mato A, Limeres J, Tomás I, Muñoz M, Abuín C, Feijoo JF, et al. Management of drooling in disabled patients with scopolamine patches. Br J Clin Pharmacol. 2010;69(6):684-8.

21. Parr JR, Todhunter E, Pennington L, Stocken D, Cadwgan J, et al. Drooling reduction intervention randomized trial (DRI): Comparing the efficacy and acceptability of hyoscine patches and glycopyrronium liquid on drooling in children with neurodisability. Arch Dis Child. 2018;103:371-6.

22. Reid SM, Westbury C, Guzys AT, Reddihough DS. Anticholinergic medications for reducing drooling in children with developmental disability. Developmental medicine Child Neurology. 2019;62(3):346-53.

23. WebMD. Scopolamine Base Transdermal System. Available on 24th March, 2020 at. https://www.webmd.com/drugs/2/drug-14032/scopolaminetransdermal/details.

24. Fairhurst CBR, Cockerill H. Management of drooling in children. Arch Dis. Child Educ. Pract Ed. 2011;96:25-30

25. Stonell TN, Greenberg J. Three treatment approaches and clinical factors in the reduction of drooling. Dysphagia. 1988;3:73-8.

26. Reddihough D, Johnson H, Ferguson E. The role of a saliva control clinic in the management of drooling. J Paediatr Child Health. 1992;28:395-7.

27. Jongerius PH, Van den Hoogen FJ, Limbeek JV, Gabree"Is FJ, Van Hulst K, Rotteveel JJ. Effect of botulinum toxin in the treatment of drooling: a controlled clinical trial. Pediatrics. 2004;114:620-7.

28. Crysdale WS. Management options for the drooling patient. Ear Nose Throat J. 1989;68(11):820. 825-6, $829-30$.

29. Van der Burg JJ, Jongerius PH, van Limbeek J, van Hulst K, Rotteveel JJ. Social interaction and self-esteem of children with cerebral palsy after treatment for severe drooling. Eur J Pediatr. 2006;165:37-41.

\section{Publisher's Note}

Springer Nature remains neutral with regard to jurisdictional claims in published maps and institutional affiliations.

Ready to submit your research? Choose BMC and benefit from:

- fast, convenient online submission

- thorough peer review by experienced researchers in your field

- rapid publication on acceptance

- support for research data, including large and complex data types

- gold Open Access which fosters wider collaboration and increased citations

- maximum visibility for your research: over $100 \mathrm{M}$ website views per year

At $\mathrm{BMC}$, research is always in progress.

Learn more biomedcentral.com/submissions 